Agrisaintifika

Jurnal Ilmu-Ilmu Pertanian

Vol. 2, No. 1, 2018

\title{
Pengaruh Imbangan Aquadest dalam Pembuatan Sabun Mandi Cair Berbahan Virgin Coconut Oil (VCO)
}

\author{
Asri Widyasanti ${ }^{1}$, Cindy Almas Ramadha ${ }^{2}$ \\ ${ }^{1,2}$ Departemen Teknik Pertanian dan Biosistem \\ Fakultas Teknologi Industri Pertanian, Universitas Padjadjaran \\ Alamat : Jl. Bandung Sumedang km 21, Jatinangor, Sumedang, 40600 \\ Email: asri.widyasanti@unpad.ac.id.
}

\begin{abstract}
ABSTRAK
Sabun merupakan surfaktan yang digunakan bersama air untuk membersihkan atau mencuci yang tersedia dalam bentuk padat dan cair. Bahan baku sabun mandi cair menggunakan minyak kelapa murni (VCO). Penelitian ini bertujuan untuk membuat sabun mandi cair, mencari jumlah imbangan aquadest yang terbaik dalam pembuatan sabun mandi cair, dan mengetahui perbandingan mutu sabun mandi cair yang dihasilkan terhadap karakteristik sabun mandi cair. Metode penelitian menggunakan metode eksperimental desain laboratorium dengan analisis deskriptif dengan pembuatan sabun metode panas. Perlakuan pada penelitian ini dengan perbedaan imbangan aquadest yang diberikan untuk pembuatan sabun mandi cair berbahan minyak kelapa murni yaitu $A=$ sabun mandi cair dengan imbangan aquadest : pasta sabun (1:1), $B=$ sabun mandi cair dengan imbangan aquadest : pasta sabun (2:1), dan $C=$ sabun mandi cair dengan imbangan aquadest : pasta sabun (3:1) dari 200 gram basis sabun. Pengamatan pada sabun mandi cair antara lain sifat fisik sabun, sifat kimia sabun, dan uji organoleptik. Hasil analisis menunjukan bahwa semua formula sabun mandi cair memenuhi persyaratan berdasarkan SNI sabun mandi cair 06-4085-1996. Formula sabun mandi cair dengan perlakuan $C$ (sabun mandi cair dengan imbangan aquadest : pasta sabun (3:1)) merupakan produk terbaik secara keseluruhan. Hasil analisis sabun mandi cair pada perlakuan $\mathrm{C}$ adalah bobot jenis 1,055 , kadar alkali bebas $0,0073 \%$, nilai $\mathrm{pH} 9,07$, nilai angka lempeng total $1 \times 10^{4} \mathrm{koloni} / \mathrm{g}$, nilai viskositas $3400 \mathrm{cPs}$, dan nilai stabilitas busa 27,66\%. Sehingga teknologi proses pembuatan sabun mandi cair dengan minyak kelapa murni dengan imbangan aquadest yang terbaik dapat dikembangkan dan diaplikasikan pada skala rumah tangga dan industri.
\end{abstract}

Kata kunci: Imbangan Aquadest, Minyak Kelapa Murni, Sabun Cair, Mutu Sabun

\section{ABSTRACT}

Soap is a surfactant that is used together with water to clean or wash in the form of solid and liquid. The raw material of liquid soap is virgin coconut oil (VCO). These research aims were to produce the formulation of liquid soap, to find the best aquadest addition in diluting liquid soap, and to compare the quality of liquid soap that being produced to its characteristics. The research methods used was an experimental laboratory with descriptive analysis using hot process soap making. The treatment of this research performed a different amount of aquadest in creating the liquid soap using virgin coconut oil based. There were three treatments applied, treatment $A$ = liquid soap with aquadest ratio: based soap of $1: 1, B=$ liquid soap with aquadest ratio: based soap of $2: 1$, and $C=$ liquid soap with aquadest ratio: based soap of 3:1 from 200 grams of soap base. The parameter observed were included physical characteristics, chemical characteristics, and organoleptic. The result showed that all liquid soap formulas met the requirements according to liquid soap standards SNI 06-4085-1996. The liquid soap formulas with treatment C (liquid soap with aquadest ratio: based soap of 3:1) revealed the best liquid soap amongst all treatments. The organoleptic test indicated that treatment $C$ had the high general preferences $43 \%$. Meanwhile, the physicochemical characteristics of the treatment $\mathrm{C}$ were 1.055 of specific gravity, free alkaline value of $0.0073 \%, \mathrm{pH}$ value of 9.07 , the total plate count value of 1 CFU/g, viscosity value of $3400 \mathrm{cPs}$, and foam stability value of $27.66 \%$. The technological process of liquid soap making using virgin coconut oil based with the best amount of an aquadest addition could be developed and be applied on soap handmade household and industrial scale.

Keywords : Aquadest ratio, Virgin Coconut Oil (VCO),Liquid Soap, Soap Quality 
Agrisaintifika

\section{PENDAHULUAN}

Seiring dengan meningkatnya pertumbuhan penduduk di Indonesia maka meningkat pula permintaan akan barangbarang untuk memenuhi kebutuhan seharihari. Berdasarkan hasil Sunsenas September 2015 Badan Pusat Statistik, persentase ratarata pengeluaran per kapita sebulan dalam rupiah dengan jenis pengeluaran bukan makanan di wilayah perkotaan lebih besar dibandingkan jenis pengeluaran makanan yaitu sebesar $54,21 \%$ dari total pengeluaran. Jenis barang kebutuhan bukan makanan bermacam-macam salah satunya adalah sabun.

Sabun merupakan surfaktan yang digunakan bersama air untuk membersihkan atau mencuci yang tersedia dalam bentuk padat dan cair. Dilihat dari segi kimia sabun adalah garam dari asam lemak atau minyak dan basa (natrium hidroksida atau kalium hidroksida). Reaksi yang terjadi disebut reaksi penyabunan atau saponifikasi (Satrias, 2010). Semakin beragamnya kebutuhan dan selera konsumen, produk sabun pun kini sangat bervariasi, seperti sabun opaque, sabun cair, dan sabun transparan. Sabun opaque adalah jenis sabun mandi biasa yang berbentuk padat dan tidak transparan, sabun cair adalah sabun mandi yang berbentuk cair, sedangkan sabun transparan adalah jenis sabun untuk muka dan untuk mandi yang dapat menghasilkan busa lebih lembut di kulit dan penampakannya berkilau jika dibandingkan dengan jenis sabun yang lain (Hambali et al, 2005).

Kelebihan lain dari sabun cair, $\mathrm{pH}$ sabun cair lebih rendah daripada sabun padat (bar soap) sehingga kulit memiliki tingkat kelembaban tinggi. Selain itu daya bersih sabun cair cukup tinggi sehingga harus lebih diperhatikan penggunaannya untuk kulit yang sensitif (Atik, 2013). Sabun yang berkualitas baik dapat dipengaruhi oleh bahan baku yang digunakan. Bahan baku utama dalam pembuatan sabun adalah lemak atau minyak dan senyawa alkali. Reaksi yang terjadi yaitu reaksi saponifikasi (tersabunkan), yang dimana gabungan antara lemak atau minyak dengan senyawa alkali akan membentuk pasta sabun. Pasta merupakan sediaan semi padat yang mengandung satu atau lebih bahan obat yang ditujukan untuk pemakaian topikal (Anief, 1993).

VCO memiliki beberapa keunggulan yang dimiliki dan bersifat mudah tersaponifikasi sehingga menjadi bahan baku yang akan digunakan. VCO merupakan minyak kelapa murni yang berasal dari olahan buah kelapa (Cocos nucifera). VCO dapat diekspor sebagai buah segar maupun produk olahanya dengan nilai ekspor yang menjanjikan dan mempunyai peluang yang besar untuk dikembangkan. Pembuatan VCO dilakukan pemurnian dengan cara pencucian menggunakan air, pengendapan, penyaringan, dan sentrifugasi. Beberapa keunggulan minyak VCO yaitu kandungan asam laurat tinggi mencapai 50\%, kandungan asam kapriat $7 \%$, komposisi asam lemak rantai mediumnya tinggi dan berat molekulnya rendah (Sutarmi, et al. 2006). VCO diperoleh dari kelapa yang sudah tua tanpa pemanasan, tanpa bahan kimia apapun, diproses secara sederhana sehingga diperoleh minyak kelapa murni yang berkualitas tinggi (Alamsyah, 2005).

Asam laurat merupakan asam lemak jenuh rantai sedang atau dalam istilah kesehatan lebih dikenal dengan medium chain fatty acid (MCFA) (Cahyono, 2010). Asam laurat sangat diperlukan dalam pembuatan sabun karena asam laurat merupakan asam lemak jenuh yang mampu memberikan sifat pembusaan yang sangat baik untuk produk sabun. Penggunaan asam laurat sebagai bahan baku akan menghasilkan sabun dengan kelarutan yang tinggi dan karakteristik busa yang baik (Shrivastava, 1982). Kandungan asam laurat yang tinggi menyebabkan VCO berkhasiat untuk menyehatkan tubuh, karena asam lemak laurat dalam tubuh bermanfaat sebagai antibiotik serta dapat meningkatkan 
Agrisaintifika

metabolisme tubuh. Penggunaan bahan alami ini diharapkan dapat menggantikan penggunaan bahan aktif sintetik yang masih digunakan pada sabun yang beredar luas di pasaran. Konsentrasi pelarutan sabun cair dengan biasanya dilakukan $15 \%-40 \%$, hal ini penting dalam menentukan mutu sabun cair. Jika pasta sabun dilarutkan dengan aquades kurang dari $15 \%$ maka busanya menjadi semakin sedikit dan kemampuan untuk membersihkannya juga semakin berkurang. Jika pasta sabun dilarutkan lebih dari $40 \%$ biasanya larutan sabun cair kembali lagi menjadi padat.

Untuk mendapatkan mutu sabun mandi cair yang diinginkan maka perlu dilakukan penelitian ini dengan memperhatikan imbangan aquadest dalam proses pembuatan sabun mandi cair. Syarat mutu sabun mandi cair yang ditetapkan Standar Nasional Indonesia (SNI) sabun yang mencakup sifat kimiawi dari sabun mandi, yaitu $\mathrm{pH}$, alkali bebas dihitung sebagai $\mathrm{KOH}$, bahan aktif, dan bobot jenis sabun. Sifat fisik sabun mandi cair meliputi bentuk, bau, dan warna (SNI,1996).

\section{BAHAN DAN METODE}

\section{Alat dan Bahan}

Alat yang digunakan yaitu timbangan digital, beaker glass, gelas ukur, kompor listrik, batang pengaduk, piknometer, $\mathrm{pH}$ indicator, $\mathrm{pH}$ meter, vortex meter, tabung reaksi, Slow cooker, pipet ukur, pipet volume, pisau, gunting, timbangan analitis, tabung reaksi, cawan petri, penangas air $45 \pm 1^{\circ} \mathrm{C}$, lemari pengeram $36 \pm 1^{\circ} \mathrm{C}$, alat penghitung koloni (colony counter), oven, cawan, erlenmeyer asah, thermometer digital, masker dan sarung tangan. Bahan yang digunakan pada saat penelitian antara lain yaitu minyak kelapa murni (VCO) yang didapatkan dari Balai Besar Industri Agro di Bogor. Bahan bahan kimia yang digunakan yaitu Kalium hydroxide $(\mathrm{KOH}) 30 \%$, gliserin, aquadest, propilena glikol, coco-DEA, etanol 96\%, phenolphtalein (PP), aseton, dietil eter, media plate count agar (PCA), buffered peptone water (BPW), dan alkohol 70\%.

\section{Tempat dan Waktu Penelitian}

Penelitian ini dilaksanakan pada bulan April 2016 hingga November 2017, bertempat di Laboratorium Pasca Panen dan Teknologi Proses, Laboratorium Kimia Pangan, Laboratorium Uji dan Laboratorium Mikrobiologi Pangan Fakultas Teknologi Industri Pertanian Universitas Padjadjaran.

\section{Metode Penelitian}

Metode penelitian yang digunakan dalam penelitian ini adalah metode eksperimental laboratorium dengan menggunakan analisis deskriptif. Metode tersebut merupakan bagian dari statistika yang mempelajari cara pengumpulan data dan penyajian data dan metode rekapitulasi hasil akhir menggunakan metode kuantitatif pembobotan.

\section{Prosedur Pembuatan Sabun Mandi Cair}

Teknik pembuatan sabun mandi dilakukan dengan metode pembuatan sabun dengan proses pemanasan (hot process). Hasil akhir pada penelitian yang telah dilakukan dengan pembuatan sabun mandi minyak kelapa murni (VCO) diperoleh basis sabun \pm 300 gram. Tahapan pembuatan pada proses pembuatan sabun mandi cair ini diantaranya persiapan bahan baku pembuatan sabun mandi cair, pembuatan sabun mandi cair dengan formulasi yang sesuai, pengujian mutu sabun mandi cair dan yang terakhir adalah menganalisis data.

Pada proses pembuatan sabun mandi cair ini diberikan imbangan aquadest : pasta sabun yang berbeda. Perlakuan sabun mandi cair minyak kelapa murni dapat diberikan sebagai berikut :

Perlakuan $\mathrm{A}=$ Sabun mandi cair dengan imbangan aquadest : pasta sabun (1:1), Perlakuan B = Sabun mandi cair dengan imbangan aquadest : pasta sabun (2: 1), Perlakuan $C=$ Sabun mandi cair dengan imbangan aquadest : pasta sabun (3 :1). 
Agrisaintifika

Jurnal Ilmu-Ilmu Pertanian

Vol. 2, No. 1, 2018

Widyasanti \& Ramadha. 2018

\section{Persiapan Bahan Baku Sabun}

Tahap awal dalam penelitian ini adalah mempersiapkan bahan-bahan untuk pembuatan sabun cair. Bahan pembuatan sabun mandi cair dapat disajikan pada Tabel 1.

Tabel 1. Bahan Pembuatan Sabun Mandi Cair

\begin{tabular}{llll}
\hline No & Bahan & $\begin{array}{l}\text { Jumlah } \\
(\mathbf{g})\end{array}$ & Fungsi \\
\hline 1. & $\begin{array}{l}\text { Minyak } \\
\text { VCO }\end{array}$ & 75 & Surfaktan \\
\hline & $\begin{array}{l}\text { Kalium } \\
\text { Hidroksida } \\
\text { (KOH) } 30 \\
\%\end{array}$ & 52,5 & Alkali bebas \\
2. & Humektan \\
\hline 3. & Gliserin & 10,25 & Humektan \\
4. & $\begin{array}{l}\text { Propilena } \\
\text { Glikol }\end{array}$ & 22,5 & $\begin{array}{l}\text { Humbut) } \\
\text { (Pelembut }\end{array}$ \\
\hline 5. & Coco-DEA & 5,46 & $\begin{array}{l}\text { Penstabil } \\
\text { busa, } \\
\text { Surfaktan }\end{array}$ \\
\hline & Aquadest & $\begin{array}{l}111,15, \\
223,00, \\
335,79\end{array}$ & Pelarut \\
\hline
\end{tabular}

Pembuatan sabun mandi cair basis minyak kelapa murni ini dilakukan dengan metode hot process. Diagram proses pembuatan sabun mandi cair disajikan pada gambar 1.

\section{Metode Analisis Sabun Mandi Cair}

Metode analisis sabun mandi cair yang akan dilakukan yaitu uji sifat fisik sabun, dan uji sifat kimia sabun dan uji organoleptik. Pengujian sifat fisik sabun meliputi bobot jenis, viskositas dan stabilitas busa. Pengukuran uji sifat kimia, yang diamati antara lain kadar alkali bebas, dan derajat keasaman $(\mathrm{pH})$ yang terkandung pada sabun yang dihasilkan. Uji sifat kimia tersebut didasarkan pada SNI 06-4085-1996 mengenai standar mutu sabun mandi cair.Uji organoleptik yang dilakukan yaitu berupa aroma, kekentalan, banyak busa/stabilitas busa, warna sabun, dan rasa kesat.

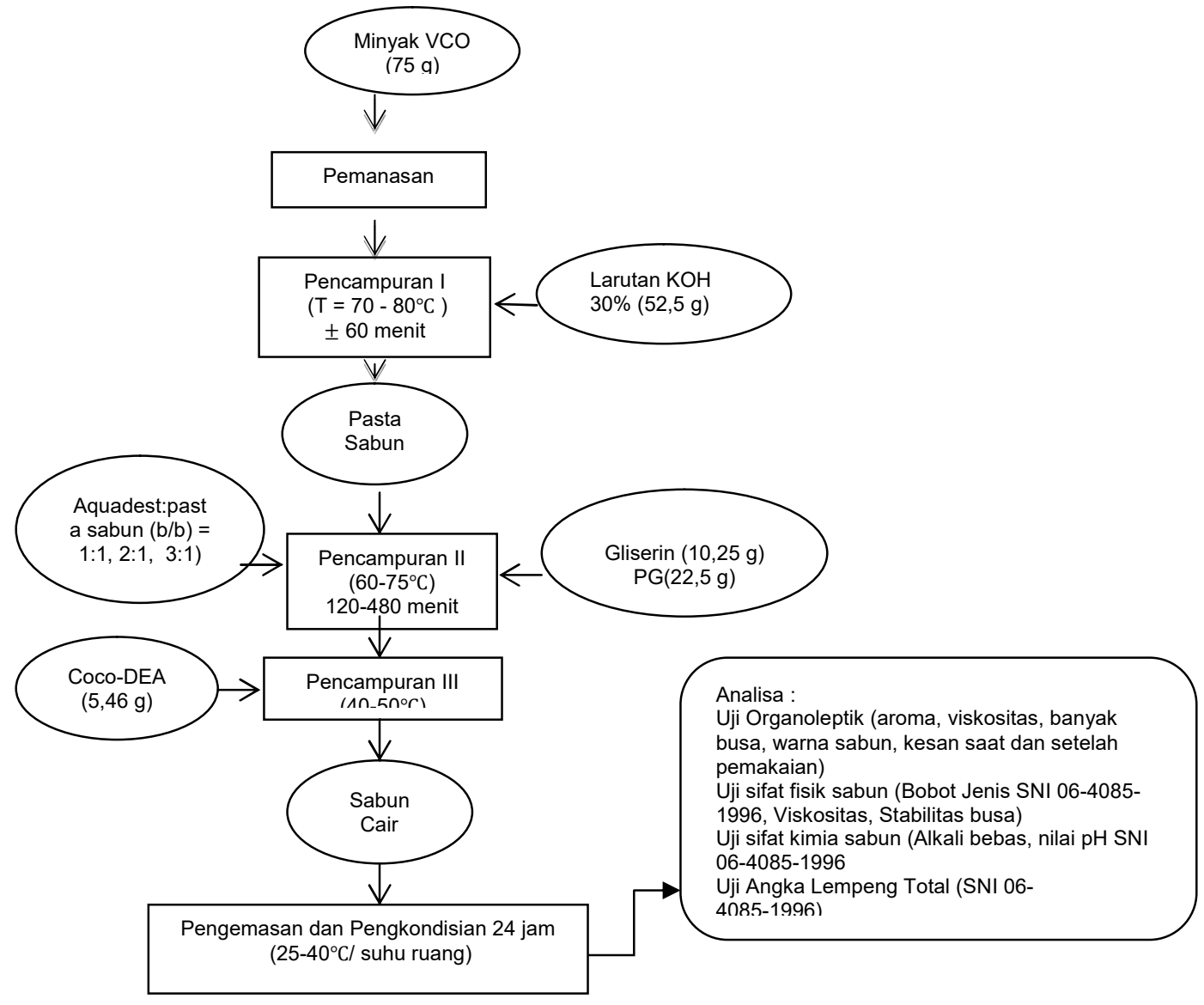

Gambar 1. Diagram Proses Pembuatan Sabun Mandi Cair 


\section{HASIL DAN PEMBAHASAN}

Sifat Fisik Sabun Mandi Cair

\section{Bobot Jenis}

Hasil pengukuran menunjukkan bobot jenis pada sabun mandi cair terendah dimiliki pada sabun mandi cair perlakuan B (sabun mandi cair dengan imbangan aquadest : pasta sabun (2:1)) yaitu sebesar 1,040 . Nilai bobot jenis tertinggi pada sabun mandi cair ditunjukkan pada sabun mandi cair perlakuan A (sabun mandi cair imbangan aquadest : pasta sabun (1:1)) yaitu mencapai 1,099 Untuk nilai bobot jenis pada sabun mandi cair $X$ (sabun mandi cair pembanding) memiliki nilai yang hampir sama dengan sabun mandi cair perlakuan B yaitu sebesar 1,047. Pengukuran bobot jenis dalam sabun mandi cair dapat dilihat pada Gambar 2.

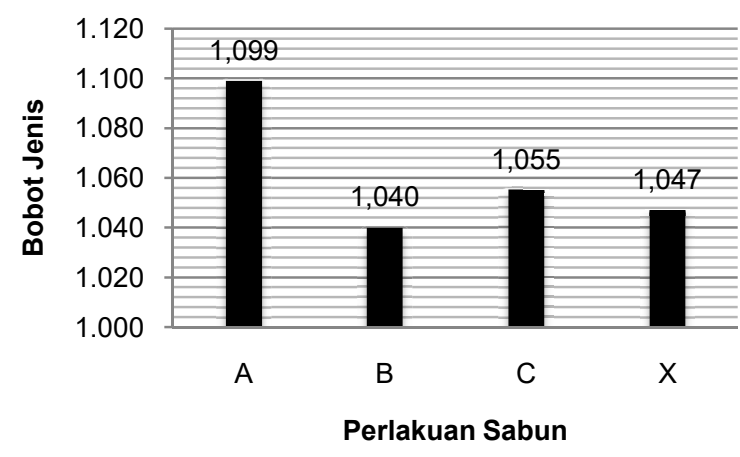

Gambar 2. Pengukuran nilai bobot jenis dalam sabun mandi cair.

Keterangan:
A : Sabun mandi cair dengan imbangan aquadest : pasta sabun (1:1)
B : Sabun mandi cair dengan imbangan aquadest : pasta sabun (2:1)
C : Sabun mandi cair dengan imbangan aquadest : pasta sabun (3:1)
$X \quad$ : Sabun mandi cair pembanding

Berdasarkan hasil pengukuran bobot jenis pada sabun mandi cair yang dilakukan, semua formula sabun mandi cair memenuhi Standar Nasional Indonesia untuk sediaan sabun cair, yaitu 1,01-1,10. Nurhadi (2012) mengatakan bahwa semakin tinggi bobot bahan baku yang ditambahkan ke dalam formulasi sabun mandi cair, maka bobot jenis produk sabun yang dihasilkan akan semakin tinggi. Gambar 2 menunjukkan bahwa semakin bertambahnya imbangan aquadest, maka nilai bobot jenis yang dihasilkan semakin menurun.Hal ini disebabkan karena peningkatan jumlah aquadest menyebabkan nilai kekentalannya turun sehingga turut mempengaruhi nilai bobot jenis pada sabun.

Pada sabun Perlakuan B (sabun mandi cair dengan imbangan aquadest : pasta sabun (2:1)) nilai bobot jenis lebih rendah dibandingan sabun perlakuan $\mathrm{C}$ (sabun mandi cair dengan imbangan aquadest : pasta sabun (3:1)), hal ini disebabkan pada saat pengujian bobot jenis sabun menggunakan piknometer sampel sabun mudah membentuk gelembung udara sehingga bobot sampel yang ditimbang akan menjadi berkurang dan dapat mempengaruhi nilai bobot jenis yang dihasilkan.

\section{Viskositas}

Analisis viskositas pada penelitian ini menggunakan viskometer brookfield dengan spindel no 61, pada kecepatan yang digunakan yaitu 3,6 , dan 12 dengan pengulangan 2 kali. Hasil analisis menunjukan bahwa viskositas yang dihasilkan berkisar antara $3400-14900$ cPs. Nilai viskositas cenderung menurun dengan penambahan imbangan aquadest. Nilai viskositas tertinggi dicapai oleh sabun mandi cair pada perlakuan A (sabun mandi cair dengan imbangan aquadest : pasta sabun (1:1)) yaitu sebesar 14900 cPs, sedangkan nilai viskositas pada sabun mandi cair yang terendah terdapat pada sabun mandi cair perlakuan C (sabun mandi cair dengan imbangan aquadest : pasta sabun (3:1)) yaitu sebesar 3400 cPs. Hubungan antara imbangan aqudest terhadap nilai viskositas 
pada sabun mandi cair dapat dilihat pada Gambar 3.

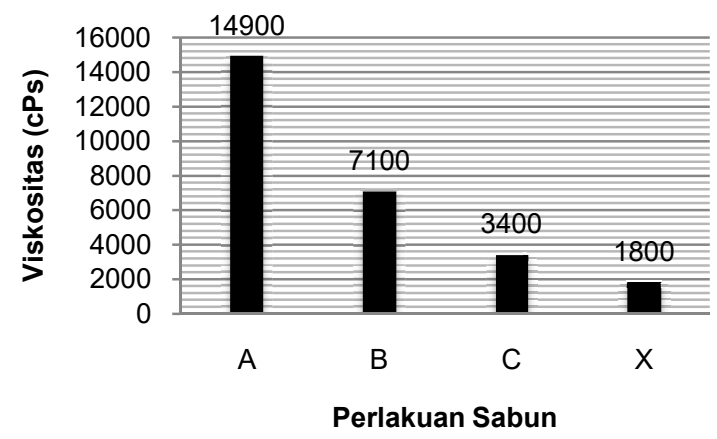

Gambar 3. Pengukuran Viskositas dalam sabun mandi cair.

Dilihat dari Gambar 3, imbangan aquadest mempengaruhi nilai viskositas pada sabun mandi cair. Semakin kecil imbangan aquadestnya, maka semakin tinggi nilai viskositas pada sabun mandi cair dan sebaliknya semakin banyak imbangan aquadest yang digunakan, maka semakin kecil nilai viskositas pada sabun mandi cair. Hasil nilai viskositas pada penelitian ini menunjukkan tidak semua nilai memenuhi standar umum untuk viskositas produk sabun mandi cair yaitu 400 - 4000 cPs (William, 2002). Dari ketiga perlakuan sabun, yang telah memenuhi syarat merupakan sabun Perlakuan C (sabun mandi cair dengan imbangan aquadest : pasta sabun (3:1)) menghasilkan nilai viskositas sebesar 3400 cPs. Jika dilihat nilai viskositas pada sabun mandi cair pembanding menghasilkan nilai yang sesusai memenuhi syaratnya.

Viskositas suatu produk bergantung pada viskositas pelarut, konstribusi bahan terlarut, dan integrasi dari keduanya. Pada penelitian kali ini perlakuan yang diberikan yaitu dengan penambahan imbangan aquadest. Karena aquadest memiliki viskositas yang sangat rendah, maka dengan penambahan imbangan aquadest nilai viskositas dari hasil pembuatan sabun mandi cair menghasilkan nilai menjadi menurun sesuai Gambar 3 yang telah ada. Semakin sedikit kandungan air dalam sabun, maka nilai viskositas semakin menaik, dan sebaliknya semakin banyak kandungan air dalarn sabun maka nila viskositas semakin menurun

\section{Stabilitas Busa}

Salah satu daya tarik sabun adalah kandungan busanya. Perilaku konsumen menunjukkan bahwa mereka akan merasa puas jika, sabun yang dipakai berbusa banyak. Analisis stabilitas busa bertujuan untuk mengetahui persentase busa yang masih tersisa dalam jangka waktu tertentu. Hasil uji stabilitas busa sabun mandi cair menunjukkan persentase stabilitas busa berkisaran antara 24,91 - 30,87 \%. Hasil uji stabilitas busa dapat dilihat pada Gambar 4.

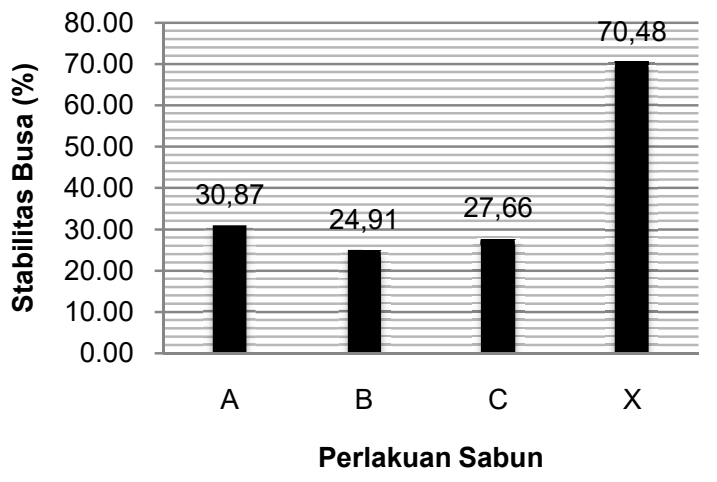

Gambar 4. Pengukuran stabilitasbusa dalam sabun mandi cair.

Busa yang tidak stabil disebabkan busa tersebut lebih mudah pecah. Pecahnya busa dikarenakan lapisan atau dinding busa menguap dan daya gravitasi menarik air dibagian atas ke arah bawah. Semakin sedikit molekul yang tidak cepat menguap, maka semakin mudah busa pengalami penguapan sehingga lebih cepat pecah. Busa akan lebih stabil bila dilapisi oleh lapisan yang tidak menguap dengan cepat seperti sabun atau lemak (Suryakusumah, 2006).

Stabilitas busa pada sabun mandi cair pada perlakuan B (sabun mandi cair pada imbangan aquadest : pasta sabun (2:1)) memiliki nilai paling kecil yaitu sebesar $24,91 \%$, sementara sabun mandi cair pada perlakuan A (sabun mandi cair pada 
imbangan : pasta sabun (1:1)) memiliki stabilitas busa yang lebih besar yaitu sebesar 30,87 . Jika dibandingkan dengan sabun mandi cair pembanding, nilai stabilitas busa pada sabun tersebut memiliki nilai yang paling tinggi, karena bahan yang terkandung pada sabun pembanding berbeda seperti kualitas bahan pada minyak VCO yang digunakan ataupun faktor lainnya.

Adanya kenaikan busa yang dihasilkan karena stabilitas busa dipengaruhi oleh $\mathrm{pH}$, sehingga semakin tinggi nilai $\mathrm{pH}$ nilai stabilitas busa yang dihasilkan juga ikut meningkat (Susinggih, 2009). Dengan penambahan imbangan aquadest yang diberikan, maka nilai stabilitas busa pada sabun cenderung menurun. Untuk nilai stabilitas busa pada sabun Perlakuan B mengalami ketidakstabilan busa sabun dapat disebabkan karena beberapa hal antara lain komposisi bahan yang tidak tepat, kecepatan dan waktu pencampuran yang tidak tepat (Cicilia, 2012).

\section{Sifat Kimia Sabun Mandi Cair}

\section{Kadar Alkali Bebas}

Sabun mandi cair yang baik yaitu sabun mandi cair yang dihasilkan dari reaksi sempurna alkali bebas dan asam lemak bebas yang diharapkan tidak residu setelah reaksi. Tetapi tidak semuanya proses pembuatan sabun mandi cair menjalani proses yang sempurna, sehingga diperlukan pengujian kadar alkali bebas dan asam lemak bebas. Asam lemak bebas diuji bila di dalam sabun mandi cair tidak terdapat alkali bebas, tetapi jika sabun mandi cair telah ditambahkan dengan indikator fenoftalein berwarna merah muda maka yang diperiksa adalah jumlah alkali bebasnya. Hubungan antara imbangan aquadest terhadap alkali bebas dalam sabun mandi cair dapat dilihat pada Gambar 5.

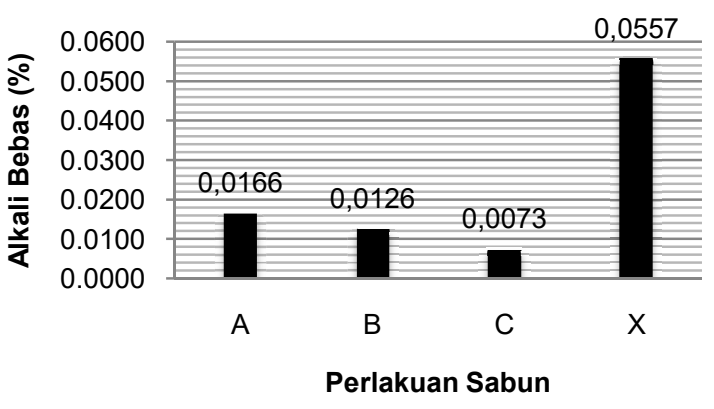

Gambar 5. Pengukuran Kadar Alkali Bebas dalam sabun mandi cair.

Setelah sabun mandi cair dilarutkan dengan alkohol netral kemudian ditambahkan indikator fenoftalein berwarna merah muda, kemudian dipanaskan dengan pendingin tegak (kondensor) selama 30 menit. Hal ini menunjukkan adanya alkali bebas pada sabun mandi cair. Sehingga uji asam lemak bebas pada sabun dikatakan negatif. Selanjutnya larutan sabun mandi cair dititrasi dengan $\mathrm{HCl} 0,1 \mathrm{~N}$ sampai larutan berwarna putih bening. Jumlah alkali bebas pada sabun mandi cair ekuivalen dengan jumlah $\mathrm{HCl}$ yang digunakan sebagai zat penitar.

Hasil grafik pada Gambar 5 kadar alkali bebas yang dihasilkan berkisar 0,0073 $0,0166 \%$. Kadar alkali bebas yang terkandung pada sabun mandi cair perlakuan A memiliki nilai yang tertinggi dibandingkan sabun mandi cair perlakuan lainnya yaitu sebesar $0,0166 \%$. Jika dibandingkan dengan sabun mandi cair pembanding, nilai kadar alkali bebas pada sabun pembanding memiliki nilai yang lebih tinggi dibandingkan sabun lainnya yaitu mencapai $0,0557 \%$. Jika dilihat dari Gambar 5, semakin bertambahnya imbangan aquadest yang digunakan maka hasil nilai kadar alkali bebas yang ada pada sabun mandi cair menurun.

Hal ini dapat disebabkan adanya reaksi alkali dengan asam-asam lemak yang terdapat pada minyak VCO sehingga reaksi penyabunan semakin sempurna, yang berdampak pada penurunan residu alkali bebas. Adanya penurunan alkali bebas ini disebabkan oleh penambahan imbangan 
aquadest yang diberikan, karena air dapat menurunkan konsentrasi alkali bebas dalam sabun (Susinggih, 2009). Dari ketiga perlakuan sabun mandi cair pada penelitian ini jika dilihat, untuk nilai kadar alkali bebas telah memenuhi syarat sesuai SNI 06-40851996 yang telah ditentukan yaitu maks 0,1\%.

\section{Nilai $\mathrm{pH}$}

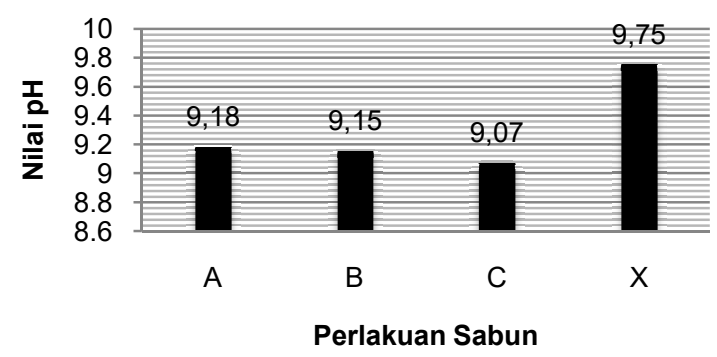

Gambar 6. Pengukuran nilai pH dalam sabun mandi cair.

Pada Gambar 6 hasil pengukuran nilai $\mathrm{pH}$ yang telah diperoleh pada sabun mandi cair dengan perlakuan $\mathrm{A}, \mathrm{B}$, dan $\mathrm{C}$ yaitu berturut turut 9,$18 ; 9,15$; dan 9,07. Sedangkan untuk nilai $\mathrm{pH}$ pada sabun mandi cair pembanding yaitu sebesar 9,75. Gambar 6 menunjukan penurunan pada nilai $\mathrm{pH}$, hal ini membuktikan bahwa semakin tinggi kadar air yang terkandung pada sabun mandi cair maka nilai $\mathrm{pH}$ akan berkurang. Nilai $\mathrm{pH}$ mempunyai kecenderungan semakin turun dengan bertambahnya imbangan aquadest yang diberikan. Nilai $\mathrm{pH}$ juga berpengaruh pada kadar alkali bebas pada sabun. Hal tersebut karena alkali yang digunakan $(\mathrm{KOH})$ bereaksi semakin sempurna dengan asamasam lemak yang terdapat dalam minyak, sehingga residu $\mathrm{KOH}$ semakin rendah dan sabun tidak lagi menjadi terlalu basa. Selain itu, peningkatan imbangan aquadest menyebabkan $\mathrm{pH}$ menurun, karena air bersifat netral sehingga dengan penambahan aquadest menyebabkan konsentrasi sabun turun dan akibatnya nilai $\mathrm{pH}$ yang menurun mendekati nilai $\mathrm{pH}$ air yang netral.

Nilai $\mathrm{pH}$ sabun dipengaruhi oleh kandungan alkali, nilai $\mathrm{pH}$ meningkat seiring dengan meningkatnya alkalinitas dan menurun seiring dengan meningkatnya keasaman (Achmad, 2004). Nilai pH yang diperoleh pada ketiga sabun mandi cair dengan perlakuan masing-masing masih memenuhi syarat mutu SNI 06-4085-1996. Sabun mandi cair yang dihasilkan dapat digunakan di skala rumah tangga untuk dijadikan sabun mandi karna $\mathrm{pH}$ yang dihasilkan sudah memenuhi syarat.

\section{Angka Lempeng Total}

Pertumbuhan mikroba dalam sabun mandi cair dapat dipengaruhi oleh faktor instrinsik dan ekstrinsik. Faktor instrinsik antara lain yaitu nilai $\mathrm{pH}$, aw, nutrisi dan senyawa antimikroba. Sedangkan faktor ekstrinsik antara lain suhu dan kelembaban relatif (Nursalam, 2003). Angka lempeng total merupakan salah satu cara untuk menentukan jumlah mikroorganisme dalam sampel secara tidak langsung. Cara ini lebih akurat dibandingkan dengan cara langsung melalui pengamatan di bawah mikroskop (Fardiaz, 1989). Cara ini berdasarkan anggapan bahwa setiap sel yang hidup akan berkembang menjadi satu koloni. Jumlah koloni yang muncul pada cawan merupakan indeks bagi mikroorganisme dalam sampel dapat hidup. Hasil jumlah cemaran mikroba dapat dilihat pada Tabel 2. 
Tabel 2. Hasil Pengujian Angka Lempeng Total Sabun Mandi Cair

\begin{tabular}{ccc}
\hline \multirow{2}{*}{ Sampel } & Pengenceran & \multicolumn{1}{c}{$\begin{array}{c}\text { Angka } \\
\text { Lempeng } \\
\text { Total } \\
\text { (Koloni/g) }\end{array}$} \\
\hline \multirow{2}{*}{$\mathrm{A}$} & $10^{-4}$ & $3,0 \times 10^{4}$ \\
\cline { 2 - 3 } & $10^{-5}$ & $5,0 \times 10^{4}$ \\
\hline \multirow{2}{*}{$\mathrm{B}$} & $10^{-4}$ & $1,5 \times 10^{4}$ \\
\cline { 2 - 3 } $\mathrm{C}$ & $10^{-5}$ & 0 \\
\hline \multirow{2}{*}{$\mathrm{C}$} & $10^{-4}$ & $1,0 \times 10^{4}$ \\
\cline { 2 - 3 } $\mathrm{X}$ & $10^{-5}$ & 0 \\
\cline { 2 - 3 } & $10^{-4}$ & $4,0 \times 10^{4}$ \\
\hline
\end{tabular}

Berdasarkan Tabel 2 dapat diketahui bahwa sabun mandi cair pada perlakuan A, $B$, dan $C$ terdapat beberapa koloni yang tumbuh setelah cawan dimasukan ke dalam inkubator selama 48 jam. Tetapi dari koloni yang dihasilkan dari perlakuan masingmasing, hasil yang didapat masih sesuai standar SNI 06-4085-1996 yang berkisar maksimal $1,0 \times 10^{5}$. Nilai angka lempeng total yang dihasilkan berpengaruh dengan imbangan aquadest yang diberikan. Sabun yang diberikan aquadest lebih banyak ternyata mempengaruhi kualitas pada sabun mandi cair tersebut mengenai cemaran mikroba yang cenderung lebih sedikit. Sabun yang memiliki kandungan airnya efektif dalam penghambatan koloni bakteri. Jika dibandingkan dengan sabun pembanding yang ada, nilai angka lempeng total pada sabun mandi cair pembanding memiliki nilai yang lebih tinggi dibandingkan sabun mandi cair pada ketiga perlakuan yang berbeda.

\section{Sifat Organoleptik Sabun Cair}

\section{Warna}

Dari hasil warna pada sabun mandi cair yang telah dibuat, ketiga warna hampir sama yaitu putih bening, tetapi setelah beberapa hari yang dilakukan penglihatan kembali. Perubahan warna pada sabun mandi cair pada perlakuan A (sabun mandi cair dengan imbangan aquadest : pasta sabun (1:1)), dan perlakuan B (sabun mandi cair dengan imbangan aquadest : pasta sabun (2:1)) mengalami perubahan yaitu menjadi berwarna putih keruh. Sehingga saat dilakukan pengujian organoleptik saat hari tersebut berpengaruh pada panelis terhadap warna sabun mandi cair. Tetapi setelah 7 hari didiamkan, warna sabun pada perlakuan $A$ dan perlakuan $B$ telah berubah warna menjadi putih bening kembali. Hal ini disebabkan karena suhu ruang penyimpanan yang terlalu rendah. Hasil pengamatan uji organoleptik untuk parameter warna pada sabun mandi cair dengan perbedaan imbangan aquades terhadap pasta sabun dapat dilihat pada Tabel 3.

Tabel 3. Penilaian Kesukaan terhadap Warna

\begin{tabular}{cc}
\hline $\begin{array}{c}\text { Sabun } \\
\text { Mandi Cair }\end{array}$ & $\begin{array}{c}\text { Rata-rata Penilaian } \\
\text { Panelis }\end{array}$ \\
\hline A & 3,43 \\
\hline B & 3,13 \\
\hline C & 3,63 \\
\hline X & 3,50 \\
\hline
\end{tabular}

Dapat diketahui data kesukaan terhadap warna sebagaian besar panelis menyatakan sangat suka pada sabun mandi cair pada perlakuan $C$ (sabun mandi cair pada imbangan aquadest : pasta sabun (3:1)), yang didapatkan dari nilai rata-rata terbesar yaitu sebesar 3,63 . Untuk urutan selanjutnya panelis memberikan nilai rata-rata terbesar kedua yaitu pada sabun perlakuan A (sabun mandi cair dengan imbangan aquadest : pasta sabun (1:1)). Nilai rata-rata terendah yang diberikan pada panelis terhadap kesukaan warna terdapat pada sabun perlakuan B (sabun mandi cair dengan imbangan aquadest : pasta sabun (2:1)) yaitu sebesar 3,13. Jika dibandingkan dengan sabun $X$ atau sabun mandi cair pembanding, nilai rata-rata yang didapat pada sabun perlakuan $\mathrm{C}$ lebih tinggi dibandingkan sabun 
X. Hal ini disebabkan karena warna sabun mandi cair perlakuan $C$ memiliki warna yang tetap putih jernih, dan bening. Sedangkan warna pada sabun $X$ (Sabun mandi cair pembanding) yaitu putih agak kekuningan dan bening. Dapat disimpulkan bahwa semakin besar imbangan aquadest yang diberikan maka warna pada sabun mandi cair yang diberikan semakin baik. Hal ini menyebabkan penilaian kesukaan panelis terhadap warna semakin bertambah.

\section{Aroma}

Penilaian terhadap aroma sabun mandi cair, dilakukan dengan cara menghirup aroma sabun mandi cair yang dihasilkan, menggunakan indera penciuman. Aroma dihirup pada bagian kepala botol kemasan. Kesan yang didapat pada saat menghirup aroma sabun mandi cair mempengaruhi persepsi konsumen. Penilaian terhadap aroma sangat subjektif dan pribadi, aroma yang tepat dipilih oleh orang lain belum tentu cocok bagi orang lain (Wasitaatmadja, 1997).

Tabel 4. Penilaian Kesukaan terhadap Aroma

\begin{tabular}{cc}
$\begin{array}{c}\text { Sabun Mandi } \\
\text { Cair }\end{array}$ & $\begin{array}{c}\text { Rata-rata Penilaian } \\
\text { Panelis }\end{array}$ \\
\hline A & 2,77 \\
\hline B & 2,83 \\
\hline C & 2,83 \\
\hline X & 2,00 \\
\hline
\end{tabular}

Dapat dilihat pada Tabel 4 tingkat kesukaan yang diberikan panelis terhadap aroma sabun mandi cair yang dihasilkan. Untuk nilai rata-rata terbesar ditunjukkan pada sabun perlakuan B dan perlakuan C yang bernilai sama yaitu sebesar 2,83 . Nilai rata-rata terkecil pada tingkat kesukaan terhadap aroma ditunjukkan pada sabun perlakuan A yaitu sebesar 2,77. Jika dibandingkan dengan sabun $X$ (sabun mandi cair pembanding) nilai rata-rata yang didapat lebih kecil dibandingkan sabun yang terbaik untuk tingkat kesukaan terhadap aroma yaitu sebesar 2,0.
Hasil analisis aroma dari panelis yang telah dilakukan menunjukkan bahwa penambahan aquadest pada pembuatan sabun mandi cair mempengaruhi hasil aroma pada sabun yang ada. Aroma yang dihasilkan memiliki bau yang khas karena sabun mandi cair mengandung minyak kelapa murni. Penelitian ini sabun mandi cair yang dibuat juga tidak adanya penambahan pewangi yang berpengaruh pada ketertarikan seseorang terhadap aroma sabun mandi cair yang dihasilkan.

\section{Kekentalan}

Kekentalan merupakan salah satu parameter yang penting untuk menunjukkan stabilitas produk (Nurhadi, 2012). Perbedaan imbangan aquadest yang diberikan pada pembuatan sabun mandi cair sangat mempengaruhi kekentalan pada produk sabun mandi cair yang dihasilkan. Respon kesukaan panelis terhadap kekentalan atau viskositas sabun mandi cair terhadap berbagai imbangan aquadest dapat dilihat pada Tabel 5.

Tabel 5. Penilaian Kesukaan terhadap Kekentalan

\begin{tabular}{cc}
\hline $\begin{array}{c}\text { Sabun Mandi } \\
\text { Cair }\end{array}$ & $\begin{array}{c}\text { Rata-rata Penilaian } \\
\text { Panelis }\end{array}$ \\
\hline A & 3,40 \\
\hline B & 3,20 \\
\hline C & 3,07 \\
\hline X & 2,20 \\
\hline
\end{tabular}

Dari data yang dihasilkan pada Tabel 5 bahwa nilai rata-rata terbesar pada tingkat kesukaan terhadap kekentalan sabun mandi cair ditunjukkan pada perlakuan A (sabun mandi cair dengan imbangan aquadest : pasta sabun (1:1)) yaitu sebesar 3,40 . Selain itu, panelis memberikan nilai rata-rata terbesar kedua ditunjukkan pada perlakuan $\mathrm{B}$ (sabun mandi cair dengan imbangan aquadest : pasta sabun (2:1)) yaitu sebesar 3,20 . Dan nilai rata-rata terkecil dari panelis yang telah diberikan untuk tingkat kesukaan 
terhadap kekentalan yaitu sabun pada perlakuan C (sabun mandi cair dengan imbangan aquadest : pasta sabun (3:1)). Untuk sabun mandi cair yang telah ada setelah dibandingkan dengan sabun $X$ (sabun mandi cair pembanding), nilai ratarata sabun $X$ yang didapat lebih rendah dari nilai sabun cair pada perlakuan lainnya yaitu sebesar 2,20.

Hasil analisis kekentalan dengan panelis menunjukkan bahwa sabun mandi cair dengan imbangan aquadest yang berbedabeda mempengaruhi kekentalan pada sabun mandi cair yang dihasilkan. Hal ini dikarenakan semakin besar imbangan aqudest yang diberikan makan hasil kekentalan yang dihasilkan semakin rendah. Dan sebaliknya semakin kecil imbangan aquadest yang diberikan maka nilai viskositas yang didapat juga semakin tinggi. Dapat disimpulkan bahwa panelis lebih menyukai sabun yang nilai kekentalannya tinggi.

\section{Banyak Busa}

Respon kesukaan panelis terhadap banyak busa sabun mandi cair dengan perbedaan imbangan aquadest yang diberikan dapat dilihat pada Tabel 6.

Tabel 6. Penilaian Kesukaan terhadap banyak busa

\begin{tabular}{ccc}
\hline No & $\begin{array}{c}\text { Sabun Mandi } \\
\text { Cair }\end{array}$ & $\begin{array}{c}\text { Rata-rata Penilaian } \\
\text { Panelis }\end{array}$ \\
\hline 1 & A & 3,53 \\
\hline 2 & B & 3,50 \\
\hline 3 & C & 3,47 \\
\hline 4 & X & 3,50 \\
\hline
\end{tabular}

Sabun mandi cair untuk tingkat kesukaan terhadap banyak busa yang dihasilkan menurut panelis nilai tingkat kesukaan yang paling tinggi ditunjukkan pada sabun Perlakuan A (Sabun mandi cair dengan imbangan aquadest : pasta sabun (1:1)) yaitu dengan rata-rata 3,53 . Sedangkan tingkat kesukaan panelis terhadap banyak busa yang terendan yaitu pada sabun Perlakuan $\mathrm{C}$
(Sabun mandi cair dengan imbangan aquadest : pasta sabun (3:1)) yaitu dengan nilai rata-rata yang didapat mencapai 3,47. Jika dibandingkan dengan sabun $X$ (sabun mandi cair pembanding) nilai rata-rata tingkat kesukaan terhadap banyak busa yang dihasilkan bernilai sama dengan sabun perlakuan B (Sabun mandi cair dengan imbangan aquadest : pasta sabun (2:1)) yaitu dengan nilai rata- rata 3,50. Dapat disimpulkan untuk perbedaan penambahan aquadest yang diberikan pada pembuatan sabun mandi cair pada penelitian ini mempengaruhi tingkat kesukaan menurut panelis. Semakin menambahnya kandungan air maka banyak busa yang dihasilkan menurut tingkat kesukaan panelis dapat dikatakan kurang baik.

\section{Kesan Saat Pemakaian}

Penilaian terhadap kesukaan kesan saat pemakaian sabun mandi cair dilakukan dengan mencuci tangan dengan sabun dan respon yang diperlihatkan oleh panelis. Respon kesukaan kesan saat pemakaian sabun mandi cair dapat dilihat pada Tabel 7 .

Tabel 7. Penilaian Kesukaan terhadap kesan saat pemakaian

\begin{tabular}{cc}
\hline $\begin{array}{c}\text { Sabun Mandi } \\
\text { Cair }\end{array}$ & $\begin{array}{c}\text { Rata-rata Penilaian } \\
\text { Panelis }\end{array}$ \\
\hline A & 3,40 \\
\hline B & 3,50 \\
\hline C & 3,47 \\
\hline X & 4,20 \\
\hline
\end{tabular}

Dari Tabel 7 penilaian panelis terhadap kesan saat pemakaian pada sabun mandi cair dengan perbedaan imbangan aquadest yang diberikan panelis untuk nilai rata-rata yang tertinggi pada sabun mandi cair yaitu pada perlakuan B (Sabun mandi cair dengan imbangan aquadest : pasta sabun (2:1)) sebesar 3,5. Selanjutnya nilai rata-rata terkecil dari panelis menurut tingkat kesukaan terhadap kesan saat pemakaian yaitu pada sabun mandi cair perlakuan A (Sabun mandi 
cair dengan imbangan aquadest : pasta sabun (1:1)) yaitu sebesar 3,40. Dari sabun mandi cair yang dihasilkan jika dibandingkan dengan sabun $X$ (sabun mandi cair pembanding) untuk tingkat kesukaan terhadap kesan saat pemakaian, sabun $X$ bernilai rata-rata yang lebih besar dibandingkan dengan sabun mandi cair lainnya yaitu mencapai 4,2.

Dapat disimpulkan kesan saat pemakaian sabun mandi cair ini diduga berdasarkan organoleptik tiap panelis yang memiliki perbedaan kesukaan secara subjektif, dengan perbedaan pemberian aquadest pada pembuatan sabun mandi cair mempengaruhi tingkat kesukaan terhadap kesan saat pemakaian pada panelis. Semakin bertambah aquadest yang diberikan maka tingkat kesukaan pada panelis terhadap saat pemakaian cenderung meningkat.

\section{Kesan Setelah Pemakaian}

Respon kesukaan kesan setelah pemakaian sabun mandi cair dapat dilihat pada Tabel 8.

Tabel 8. Penilaian Kesukaan terhadap kesan setelah pemakaian

\begin{tabular}{ccc}
\hline No & $\begin{array}{c}\text { Sabun Mandi } \\
\text { Cair }\end{array}$ & $\begin{array}{c}\text { Rata-rata Penilaian } \\
\text { Panelis }\end{array}$ \\
\hline 1 & A & 3,30 \\
\hline 2 & B & 3,37 \\
\hline 3 & C & 3,40 \\
\hline 4 & X & 2,70 \\
\hline
\end{tabular}

Dari hasil yang didapat pada Tabel 8 , kesan setelah pemakaian sabun mandi cair menunjukkan bahwa nilai rata-rata terbesar ditunjukkan pada sabun mandi cair pada perlakuan $C$ (sabun mandi cair dengan imbangan aquadest : pasta sabun (3:1)) yaitu sebesar 3,40. Nilai rata-rata terbesar kedua yang diberikan para panelis ditunjukkan pada sabun mandi cair perlakuan B (sabun mandi cair dengan imbangan aquadest : pasta sabun (2:1)). Selanjutnya, nilai rata-rata terkecil yang diberikan oleh panelis ditunjukkan pada sabun mandi cair perlakuan A (sabun mandi cair dengan imbangan aquadest : pasta sabun (1:1)). Dari ketiga perlakuan sabun yang berbeda, hasilnya tidak begitu jauh untuk besar nilainya. Jika dibandingkan dengan sabun $X$ (sabun mandi cair pembanding), nilai rata-rata yang diberikan panelis berdasarkan tingkat kesukaan terhadap kesan setelah pemakaian menghasilkan nilai yang lebih kecil dibandingkan ketiga perlakuan sabun mandi cair lainnya yaitu sebesar 2,70.

Berdasarkan presentase penilaian kesukaan panelis terhadap kesan setelah pemakaian sabun mandi cair menunjukkan bahwa panelis memberikan respon kesukaan paling besar yang diberikan pada sabun perlakuan C (sabun mandi cair dengan imbangan aquadest : pasta sabun (3:1)). Semakin tinggi pemberian aquadest yang diberikan pada pembuatan sabun mandi cair maka hasil penilaian kesukaan kesan setelah pemakaian berpengaruh yang baik untuk panelis yang telah menggunakan produk sabun mandi cair yang dibuat.

\section{Kesukaan Secara Umum}

Setelah melakukan uji organoleptik pada panelis dengan penilaian kesukaan terhadap warna, aroma, kekentalan, banyak busa, kesan saat pemakaian, dan kesan setelah pemakaian selanjutnya penilaian secara umum sabun mandi cair yang dihasilkan. Produk sabun mandi cair yang dihasilkan diurutkan dari ranking 1 hingga rangking 3 , yaitu sabun yang paling disukai sampai sabun yang tidak disukai. Respon kesukaan panelis secara umum pada sabun mandi cair terhadap perbedaan imbangan aquades yang diberikan dapat dilihat pada Tabel 9. 
Widyasanti \& Ramadha. 2018

Tabel 9. Penilaian Kesukaan Sabun Mandi Cair Secara Umum

\begin{tabular}{cccc}
\hline Keterangan & $\begin{array}{c}\text { Perlaku } \\
\text { an A } \\
(\%)\end{array}$ & $\begin{array}{c}\text { Perlaku } \\
\text { an B } \\
(\%)\end{array}$ & $\begin{array}{c}\text { Perlak } \\
\text { uan C } \\
(\%)\end{array}$ \\
\hline Rangking 1 & $33 \%$ & $20 \%$ & $43 \%$ \\
\hline Rangking 2 & $27 \%$ & $50 \%$ & $27 \%$ \\
\hline Rangking 3 & $40 \%$ & $30 \%$ & $30 \%$ \\
\hline
\end{tabular}

Pada Tabel 9 menunjukkan bahwa sabun terbaik berdasarkan presentase kesukaan secara umum sebanyak $43 \%$ panelis menyatakan sabun mandi cair perlakuan C (sabun mandi cair dengan imbangan aquadest : pasta sabun (3:1)) menempati rangking 1 . Selanjutnya peringkat 2 ditempati pada sabun mandi cair perlakuan B (sabun mandi cair dengan imbangan aquadest : pasta sabun (2:1)) mencapai $50 \%$. Kemudian pada peringkat 3 ditempati pada perlakuan A (Sabun mandi cair dengan imbangan aquadest : pasta sabun (1:1)) yaitu sebesar $40 \%$. Semakin besar imbangan aquadest yang digunakan maka kekentalan dan banyak busa yang dihasilkan pada sabun mandi cair akan berkurang sehingga berpengaruh pada hasil tingkat kesukaan pada panelis. Tingkat kesukaan pada warna, aroma, kesan saat pemakaian dan setelah pemakaian juga berpengaruh menurut panelis. Hal ini disebabkan dengan beberapa faktor yang ada saat penelitian.

\section{Rekapitulasi Hasil Mutu Sabun Mandi Cair}

Hasil analisis dari uji mutu sabun mandi cair pada setiap perlakuan dengan berbagai imbangan aquadest yang diberikan direkapitulasi dan dibandingkan dengan standar yang ada. Standar yang digunakan pada pengujian mutu sabun mandi cair yaitu Standar Nasional Indonesia 06-4085-1996. Rekapitulasi hasi dan mutu sini dibandingkan produk sabun mandi cair yang telah dibuat dengan produk sabun mandi cair yang telah dipasarkan akan dijadikan standar untuk persyaratan dari jenis uji yang tidak disyaratkan dalam SNI. Berikut merupakan hasil rekapitulasi yang disajikan pada Tabel 10.

Untuk menentukan perlakuan terbaik pada hasil penelitian dilakukan dengan terlebih dahulu melakukan penentuan skor pada masing-masing parameter yang menggunakan perhitungan metode kuantitatif dengan menentukan persentase bobot kepentingan dari masing - masing parameter. Sehingga hasil rekapitulasi perolehan skor menurut analisis uji mutu sabun mandi cair terdapat pada Tabel 11.

Tabel 10. Rekapitulasi Hasil Analisis Mutu Sabun Mandi Cair

\begin{tabular}{|c|c|c|c|c|c|c|}
\hline \multirow[t]{2}{*}{$\begin{array}{c}\text { Parame } \\
\text { ter }\end{array}$} & \multicolumn{3}{|c|}{$\begin{array}{c}\text { Hasil Analisis } \\
\text { Perlakuan Perbedaan } \\
\text { Imbangan Aquadest } \\
\text { pada Sabun Mandi } \\
\text { Cair } \\
\end{array}$} & \multirow[t]{2}{*}{$X$} & \multirow[t]{2}{*}{$\begin{array}{l}\text { Stand } \\
\text { ar }\end{array}$} & \multirow[t]{2}{*}{$\begin{array}{c}\text { Keteran } \\
\text { gan }\end{array}$} \\
\hline & $A$ & $B$ & $\mathrm{C}$ & & & \\
\hline $\begin{array}{l}\text { Bobot } \\
\text { Jenis }\end{array}$ & $\begin{array}{c}1,09 \\
9\end{array}$ & $\begin{array}{c}1,04 \\
0\end{array}$ & $\begin{array}{c}1,05 \\
5\end{array}$ & $\begin{array}{c}1,04 \\
7\end{array}$ & $\begin{array}{c}1,01 \\
- \\
1,10 \\
\end{array}$ & $\begin{array}{c}\text { Sesuai } \\
\text { Standar } \\
\text { SNI }\end{array}$ \\
\hline $\begin{array}{c}\text { Viskosit } \\
\text { as } \\
(\mathrm{cPs})\end{array}$ & $\begin{array}{c}1490 \\
0\end{array}$ & 7100 & 3400 & 1800 & $\begin{array}{c}40- \\
4000\end{array}$ & $\begin{array}{c}\text { Williams } \\
2002\end{array}$ \\
\hline $\begin{array}{c}\text { Stabilita } \\
\text { s Busa } \\
(\%)\end{array}$ & $\begin{array}{c}30,8 \\
7\end{array}$ & $\begin{array}{c}24,9 \\
1\end{array}$ & $\begin{array}{c}27,6 \\
6\end{array}$ & $\begin{array}{c}70,4 \\
8\end{array}$ & - & - \\
\hline $\begin{array}{c}\text { Kadar } \\
\text { Alkali } \\
\text { Bebas } \\
(\%)\end{array}$ & $\begin{array}{c}0,01 \\
66\end{array}$ & $\begin{array}{c}0,01 \\
26\end{array}$ & $\begin{array}{c}0,00 \\
73\end{array}$ & $\begin{array}{c}0,05 \\
57\end{array}$ & $\begin{array}{c}\text { Maks. } \\
0,1\end{array}$ & $\begin{array}{c}\text { Sesuai } \\
\text { Standar } \\
\text { SNI }\end{array}$ \\
\hline Nilai pH & 9,2 & 9,17 & 9,07 & 9,75 & $8-11$ & $\begin{array}{c}\text { Sesuai } \\
\text { Standar } \\
\text { SNI }\end{array}$ \\
\hline $\begin{array}{c}\text { Angka } \\
\text { Lempe } \\
\text { ng } \\
\text { Total } \\
\text { (koloni/ } \\
\text { g) }\end{array}$ & $\begin{array}{l}4 \times \\
10^{4}\end{array}$ & $\begin{array}{c}1,5 \\
\times \\
10^{4}\end{array}$ & $\begin{array}{c}1 \times \\
10^{4}\end{array}$ & $\begin{array}{l}7 \times \\
10^{4}\end{array}$ & $\begin{array}{c}\text { Maks } \\
1 \times \\
10^{5}\end{array}$ & $\begin{array}{c}\text { Sesuai } \\
\text { Standar } \\
\text { SNI }\end{array}$ \\
\hline
\end{tabular}


Widyasanti \& Ramadha. 2018

Tabel 11. Rekapitulasi Perolehan Skor Uji MutuSabun

\begin{tabular}{|c|c|c|c|c|c|c|c|}
\hline \multirow[b]{2}{*}{$\begin{array}{c}\text { Sabu } \\
n \\
\text { Mand } \\
\text { i Cair }\end{array}$} & \multicolumn{6}{|c|}{$\begin{array}{l}\text { Hasil Analisis Perlakuan Perbedaan } \\
\text { Imbangan Aquadest : Pasta Sabun }\end{array}$} & \multirow[b]{2}{*}{$\begin{array}{l}\text { Tot } \\
\text { al } \\
\text { Sk } \\
\text { or }\end{array}$} \\
\hline & $\begin{array}{c}\text { Bob } \\
\text { ot } \\
\text { Jeni } \\
s\end{array}$ & $\begin{array}{c}\text { Visk } \\
\text { osit } \\
\text { as }\end{array}$ & $\begin{array}{c}\text { Stabili } \\
\text { tas } \\
\text { Busa }\end{array}$ & $\begin{array}{c}\text { Kada } \\
r \\
\text { Alkali } \\
\text { Beba } \\
\text { s }\end{array}$ & $\mathrm{pH}$ & $\begin{array}{c}\text { Angka } \\
\text { Lempe } \\
\text { ng } \\
\text { Total }\end{array}$ & \\
\hline$A$ & 1 & 1 & 3 & 1 & 1 & 1 & 8 \\
\hline B & 3 & 2 & 1 & 2 & 1 & 2 & 11 \\
\hline C & 3 & 3 & 2 & 3 & 3 & 3 & 17 \\
\hline
\end{tabular}

Adapun presentase bobot kepentingan pada masing - masing parameter disajikan pada Tabel 12.

Tabel 12. Presentase Bobot Kepentingan Parameter Mutu Sabun Mandi Cair

\begin{tabular}{cc}
\hline Parameter & $\begin{array}{c}\text { Presentase Bobot } \\
\text { Kepentingan }\end{array}$ \\
\hline Bobot Jenis & $5 \%$ \\
\hline Viskositas (cPs) & $20 \%$ \\
\hline Stabilitas Busa (\%) & $10 \%$ \\
\hline $\begin{array}{c}\text { Kadar Alkali Bebas } \\
(\%)\end{array}$ & $20 \%$ \\
\hline Nilai pH & $20 \%$ \\
\hline $\begin{array}{c}\text { Angka Lempeng } \\
\text { Total (koloni/g) }\end{array}$ & $25 \%$ \\
\hline
\end{tabular}

Parameter angka lempeng total diberikan presentase bobot kepentingan tertinggi yaitu sebesar 25\%. Hal ini disebabkan karena sabun mandi yang baik memiliki jumlah cemaran mikroba yang kecil atau tidak adanya mikroba sama sekali. Parameter terpenting kedua yaitu pada parameter viskositas, kadar alkali bebas, dan nilai $\mathrm{pH}$ yang dimana masing - masing bobot kepentingan yang diberikan sebesar $20 \%$. Dimana menurut sifat fisik atau wujud pemilihan pada sabun didasari dengan kekentalan yang sesuai dan dengan pemberian perlakuan dengan imbangan aquadest mempengaruhi karakteristik viskositas sabun. Untuk nilai kadar alkali bebas mempengaruhi nilai $\mathrm{pH}$ pada sabun itu sendiri. Nilai $\mathrm{pH}$ yang tinggi mengakibatkan iritasi pada kulit pengguna akibatnya kadar alkali bebas pada sabun tersebut juga tinggi. Selanjutnya parameter terpenting ketiga yaitu stabilitas busa yang diberikan bobot kepentingan yaitu sebesar $10 \%$. Karena sabun yang baik memiliki stabilitas busa sabun yang tinggi tetapi belum tentu baik untuk tingkat kebersihannya. Penambangan stabilitas busa dapat dipengaruhi kualitas bahan sabun yang digunakan. Parameter terpenting yang terakhir yaitu bobot jenis diberikan presentase bobot kepentingan sebesar $5 \%$. Untuk sifat fisik pada bobot jenis tidak begitu mempengaruhi pemilihan sabun mandi pada konsumen.

Setelah dilakukan penentuan presentase bobot kepentingan dari masing - masing parameter, hasil perolehan skor yang telah dipaparkan pada Tabel 11 disesuaikan dengan presentase bobot kepentingan yang telah ditetapkan pada Tabel 12. Hasil rekapitulasi skor berdasarkan persentase bobot kepentingan disajikan pada Tabel 13 .

Tabel 13. Rekapitulasi Total Skor Persentase Bobot Kepentingan Hasil Mutu SabunMandi Cair

\begin{tabular}{|c|c|c|c|c|c|c|c|}
\hline \multirow[b]{2}{*}{$\begin{array}{c}\text { Sab } \\
\text { un } \\
\text { Man } \\
\text { di } \\
\text { Cair }\end{array}$} & \multicolumn{6}{|c|}{$\begin{array}{l}\text { Hasil Analisis Perlakuan Perbedaan } \\
\text { Imbangan Aquadest : Pasta Sabun }\end{array}$} & \multirow[b]{2}{*}{$\begin{array}{l}\text { Total } \\
\text { Skor }\end{array}$} \\
\hline & $\begin{array}{c}\text { Bob } \\
\text { ot } \\
\text { Jeni } \\
\text { s }\end{array}$ & $\begin{array}{l}\text { Visko } \\
\text { sitas }\end{array}$ & $\begin{array}{c}\text { Stabilit } \\
\text { as } \\
\text { Busa }\end{array}$ & $\begin{array}{c}\text { Kad } \\
\text { ar } \\
\text { Alka } \\
\text { li } \\
\text { Beb } \\
\text { as }\end{array}$ & $\mathrm{pH}$ & $\frac{\mathrm{AL}}{\mathrm{T}}$ & \\
\hline$A$ & 0,05 & 0,20 & 0,30 & 0,20 & 0,20 & 0,25 & 1,20 \\
\hline$B$ & 0,15 & 0,40 & 0,10 & 0,40 & 0,20 & 0,50 & 1,75 \\
\hline $\mathrm{C}$ & 0,15 & 0,60 & 0,20 & 0,60 & 0,60 & 0,75 & 2,90 \\
\hline
\end{tabular}

Berdasarkan hasil rekapitulasi total skor berdasarkan persentase bobot kepentingan yang telah tertera pada Tabel 25 , hasil yang memperoleh nilai skor tertinggi ditunjukkan pada sabun Perlakuan $\mathrm{C}$ (sabun mandi cair dengan imbangan aquades : pasta sabun 3:1). Sehingga dapat disimpulkan bahwa sabun Perlakuan $\mathrm{C}$ adalah sabun yang terbaik menurut mutunya. 
Agrisaintifika

Jurnal Ilmu-Ilmu Pertanian

Vol. 2, No. 1, 2018

Widyasanti \& Ramadha. 2018

\section{KESIMPULAN}

Pembuatan sabun mandi cair berbasis minyak kelapa murni (VCO) dilakukan dengan metode hot processdengan pemberian imbangan aquadest yang berbeda sesuai perlakuan. Beberapa faktor yang mempengaruhi mutu pada proses pembuatan sabun mandi cair yaitu formulasi sabun mandi cair, proses pengadukan, proses pencampuran bahan, suhu yang digunakan saat pembuatan, dan waktu pembuatan sabun mandi cair. Hasil analisis uji mutu sabun mandi cair berdasarkan standar mutu sesaui SNI 06-4085-1996 dari ketiga perlakuan dengan perbedaan imbangan aquadest telah memenuhi standar. Hasil uji mutu yang terbaik ditunjukkan pada sabun mandi cair Perlakuan C (sabun mandi cair dengan imbangan aquadest : pasta sabun (3:1) yaitu nilai viskositas $3400 \mathrm{cPs}$, kadar alkali bebas $0,0073 \%$, nilai $\mathrm{pH} 9,07$ dan angka lempeng total $1 \times 10^{4} \mathrm{koloni} / \mathrm{g}$, dan hasil organoleptik yang terbaik juga ditunjukkan pada sabun Perlakuan $\mathrm{C}$ (sabun mandi cair dengan imbangan aquadest : pasta sabun (3:1).

\section{DAFTAR PUSTAKA}

Achmad, R., 2004. Kimia Lingkungan. PenerbitAndi, Yogyakarta.

Alamsyah. 2005. Virgin Coconut Oil MinyakPenakluk Aneka Penyakit, Penerbit Agro Media Pustaka, Jakarta.

Anief, M. 1993. Farmasetika. Gadjah Mada University Press, Yogyakarta.

Atik. 2013. MembuatSabunMandiSendiri [internet]. [diunduh 2016 Januari 25) Tersediapada

:http://www.putraindonesiamalang.or.i $\mathrm{d} /$ membuat-sabun-mandi-cair-sendirikenapa-tidak.html

Badan Standarisasi Nasional, 1996. Standar Sabun Mandi Cair, SNI 06-4085-1996, Dewan Standarisasi Nasional, Jakarta

Cahyono. 2010. Proses PembuatanVirgin Coconut

OildenganFermentasiMenggunkan
Starter Ragi Tempe.

UniversitasDiponegoro. Semarang.

Cicilia, Siely. 2012.

PembuatanSabunMandiCair Gel

AlamidenganBahanAktifMikroalga.

TugasAkhir. Malang. Universitas $\mathrm{Ma}$ Chung.

Fardiaz, S. 1989. Mikrobiologi Pangan. Pusat Antar Universitas. Institut Pertanian Bogor, Bogor

Hambali, E., Suryani, A. dan Rifai M., 2005, Membuat Sabun Tranparan untuk Gift dan Kecantikan, 19-23, Penebar Swadaya, Jakarta.

Nurhadi, S.C., 2012, Pembuatan Sabun Mandi Gel Alami dengan Bahan Aktif Mikroalga Chlorrela pyrenoidosa Beyerinck dan Minyak Atsiri Lavandula lativolia Chaix, Skripsi, Program Studi Teknik Industri Fakultas Sains dan Teknologi, Universitas Ma Chung, Malang.

Nursalam, 2003. Konsep dan Penerapan Metodologi IImu Keperawatan Pedoman skripsi, Tesis dan Instrumen Penelitian Keperawatan. Salemba Medika, Jakarta.

Satrias. 2010. Formulasi Sabun Mandi Cair yang Mengandung Gel Daun Lidah Buaya (Aloe vera (L.)Webb) dengan Basis Virgin Coconut Oil (VCO). Skripsi. Program Studi Farmasi, FMIPA - Universitas Islam Bandung.

Shrivastava, S.B., 1982, Soap, Detergent and Perfume Industry, Small Industry Research Institute, New Delhi.

Suryakusumah. 2006. Aplikasi Agar-Agar Rumput Laut Gelidium sp. Sebagai Pengental Pada Formulasi Sabun Mandi Cair. Penerbit Perikanan dan IImu Kelautan - Institut Pertanian Bogor.

Susinggih. 2009. Studi Pembuatan Sabun Mandi Cair dari Daur Ulang Minyak Goreng Bekas (Kajian Pengaruh Lama Pengadukan dan Rasio Air:Sabun Terhadap Kualitas). Penerbit Teknologi Pertanian - Universitas Brawijaya.

Sutarmi dan Rozaline H. 2005. Taklukan Penyakit Dengan VCO (Virgin Coconut Oil). Penebar Swadaya. Depok.

Wasitaatmadja, S.M. 1997. Penuntun IImu Kosmetik Medik. Univertas Indonesia, 
Agrisaintifika

Jurnal Ilmu-Ilmu Pertanian

Vol. 2, No. 1, 2018

Widyasanti \& Ramadha. 2018

Jakarta

Williams. 2002, Kimia dan Teknologi Industri Kosmetika dan
Perawatan Diri. Terjemahan. FATETA, IPB, Bogor. 